\title{
Halogens as tracers of protosolar nebula material in comet 67P/Churyumov-Gerasimenko
}

Frederik Dhooghe, ${ }^{1 \star}$ Johan De Keyser, ${ }^{1,2 \star}$ Kathrin Altwegg, ${ }^{3,4}$ Christelle Briois, ${ }^{5}$ Hans Balsiger, ${ }^{3}$ Jean-Jacques Berthelier, ${ }^{6}$ Ursina Calmonte, ${ }^{3}$ Gaël Cessateur, ${ }^{1}$ Michael R. Combi, ${ }^{7}$ Eddy Equeter, ${ }^{1}$ Björn Fiethe, ${ }^{8}$ Nicolas Fray, ${ }^{9}$ Stephen Fuselier, ${ }^{10,11}$ Sébastien Gasc, ${ }^{3}$ Andrew Gibbons, ${ }^{1,12}$ Tamas Gombosi, ${ }^{7}$ Herbert Gunell, ${ }^{1}$ Myrtha Hässig,,${ }^{3,10}$ Martin Hilchenbach, ${ }^{13}$ Léna Le Roy, ${ }^{4}$ Romain Maggiolo, ${ }^{1}$ Urs Mall, ${ }^{13}$ Bernard Marty, ${ }^{14}$ Eddy Neefs, ${ }^{1}$ Henri Rème, ${ }^{15,16}$ Martin Rubin, ${ }^{3}$ Thierry Sémon, ${ }^{3}$ Chia-Yu Tzou ${ }^{3}$ and Peter Wurz ${ }^{3,4}$

${ }^{1}$ Royal Belgian Institute for Space Aeronomy, BIRA-IASB, Ringlaan 3, B-1180 Brussels, Belgium

${ }^{2}$ Center for mathematical Plasma Astrophysics, KULeuven, Celestijnenlaan 200B, B-3001 Heverlee, Belgium

${ }^{3}$ Physikalisches Institut, University of Bern, Sidlerstr. 5, CH-3012 Bern, Switzerland

${ }^{4}$ Center for Space and Habitability, University of Bern, Sidlerstr. 5, CH-3012 Bern, Switzerland

${ }^{5}$ Laboratoire de Physique et Chimie de l'Environnement et de l'Espace (LPC2E), UMR CNRS 7328, Université d'Orléans, Avenue de la Recherche Scientifique 3A, F-45071 Orléans, France

${ }^{6}$ LATMOS/IPSL-CNRS-UPMC-UVSQ, 4 Avenue de Neptune, F-94100 Saint-Maur, France

${ }^{7}$ Department of Climate and Space Sciences and Engineering, University of Michigan, 2455 Hayward, Ann Arbor, MI 48109, USA

${ }^{8}$ Institute of Computer and Network Engineering (IDA), TU Braunschweig, Hans-Sommer-Straße 66, D-38106 Braunschweig, Germany

${ }^{9}$ Laboratoire Interuniversitaire des Systèmes Atmosphériques (LISA), UMR CNRS 7583, Université Paris-Est Créteil (UPEC), Université Paris Diderot (UPD), Rue Thomas Mann 5, F-75013 Paris, France

${ }^{10}$ Space Science Directorate, Southwest Research Institute, 6220 Culebra Rd., San Antonio, TX 78228, USA

${ }^{11}$ University of Texas at San Antonio, San Antonio, TX 78228, USA

${ }^{12}$ Service de Chimie Quantique et Photophysique, Université Libre de Bruxelles, 50 Avenue F. Roosevelt, B-1050 Brussels, Belgium

${ }^{13}$ Max-Planck-Institut für Sonnensystemforschung, Justus-von-Liebig-Weg 3, D-37077 Göttingen, Germany

${ }^{14}$ Centre de Rech. Pétrographiques and Géochimiques, CRPG-CNRS, Univ. Lorraine, 15 rue N. D. des Pauvres, BP 20, F-54501 Vandoeuvre lès Nancy, France

${ }^{15}$ Université de Toulouse; UPS-OMP; IRAP, 9 Avenue du Colonel Roche, F-31400 Toulouse, France

${ }^{16}$ Institut de Recherches en Astrophysique et Planétologie, CNRS-IRAP; 9 Avenue du Colonel Roche, BP 44346, F-31028 Toulouse Cedex 4, France

Accepted 2017 July 25. Received 2017 July 3; in original form 2017 March 30

\begin{abstract}
We report the first in situ detection of halogens in a cometary coma, that of 67P/ChuryumovGerasimenko. Neutral gas mass spectra collected by the European Space Agency's Rosetta spacecraft during four periods of interest from the first comet encounter up to perihelion indicate that the main halogen-bearing compounds are $\mathrm{HF}, \mathrm{HCl}$ and $\mathrm{HBr}$. The bulk elemental abundances relative to oxygen are $\sim 8.9 \times 10^{-5}$ for $\mathrm{F} / \mathrm{O}, \sim 1.2 \times 10^{-4}$ for $\mathrm{Cl} / \mathrm{O}$ and $\sim 2.5 \times 10^{-6}$ for $\mathrm{Br} / \mathrm{O}$, for the volatile fraction of the comet. The cometary isotopic ratios for ${ }^{37} \mathrm{Cl} /{ }^{35} \mathrm{Cl}$ and ${ }^{81} \mathrm{Br} /{ }^{79} \mathrm{Br}$ match the Solar system values within the error margins. The observations point to an origin of the hydrogen halides in molecular cloud chemistry, with frozen hydrogen halides on dust grains, and a subsequent incorporation into comets as the cloud condensed and the Solar system formed.
\end{abstract}

Key words: methods: data analysis - methods: observational - space vehicles: instruments comets: general -comets: individual: 67P/Churyumov-Gerasimenko-composition.

*E-mail: frederik.dhooghe@aeronomie.be (FD); johan.dekeyser@ aeronomie.be (JDeK)

\section{INTRODUCTION}

While molecular clouds evolve from diffuse to dense and ultimately protostellar clouds, the halogens that initially are present in atomic form become bound in hydrogen halides. Atomic fluorine in diffuse molecular clouds reacts exothermically with the abundant $\mathrm{H}_{2}$ 


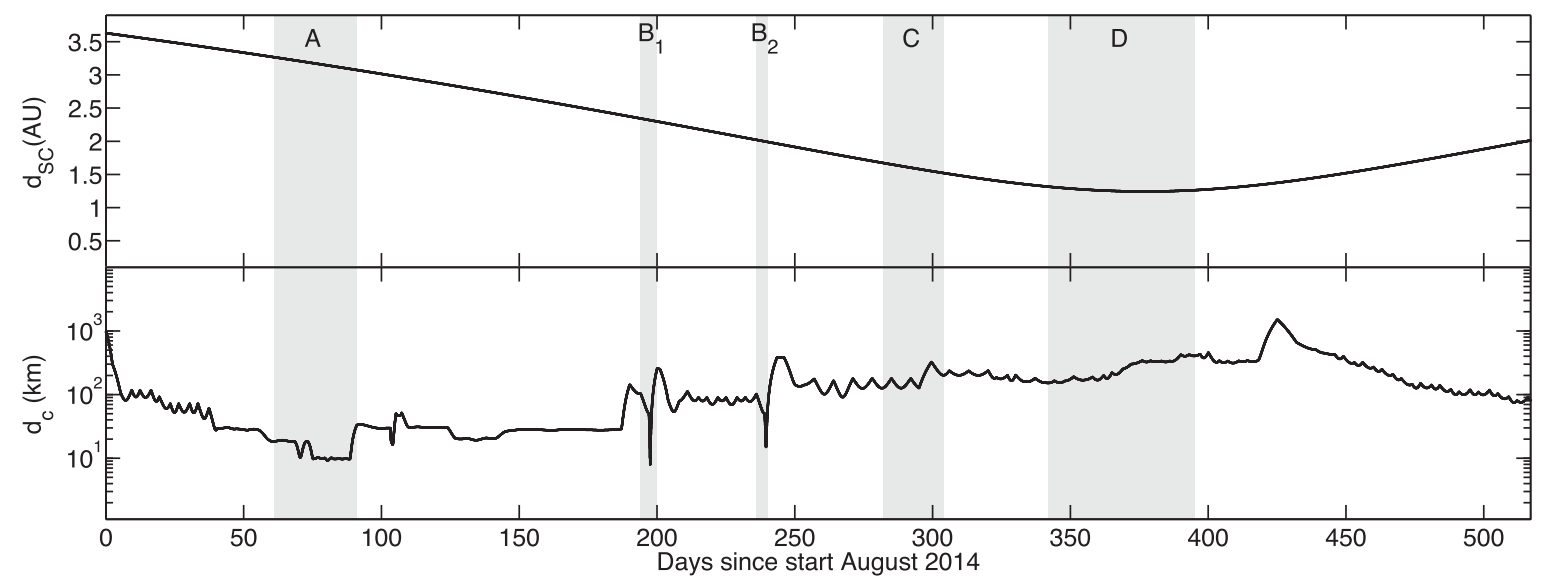

Figure 1. Sun-comet and comet-spacecraft distance for the periods of interest. The plot covers 2014 August 1 to 2015 December 31 . The shaded areas indicate the periods (A) close to the comet, 2014 October 1-31, (B1 and B2) the close flybys on 2015 February 14 and on 2015 March 28, (C) post-equinox between 2015 May 10 and June 1 and (D) around perihelion between 2015 July 9 and August 31.

and readily forms HF. The reaction of atomic chlorine and bromine with $\mathrm{H}_{2}$-forming $\mathrm{HCl}$ and $\mathrm{HBr}$ is endothermic but still occurs easily in dense molecular clouds where free energy is available in the form of thermal energy or photons (Neufeld \& Wolfire 2009). Therefore, the principal reservoirs of halogens in protostellar clouds are thought to be the hydrogen halides. This was suggested for $\mathrm{HCl}$ by Jura (1974) and Dalgarno et al. (1974). Astronomical detection of $\mathrm{HCl}$ in such clouds indicates that it is strongly depleted in the gas phase (Blake, Keene \& Phillips 1985), which suggests that $\mathrm{HCl}$ is frozen out on grains in these cold environments (Peng et al. 2010; Emprechtinger et al. 2012). Kama et al. (2015) presented the first gas-grain chemical model for chlorine. Using data of various chlorine species from the Herschel Space Observatory and from the Caltech Submillimeter Observatory, they estimate that in protostellar cores at least 90 per cent of the full chlorine inventory is locked in $\mathrm{HCl}$ ice. $\mathrm{HF}$ has been detected in diffuse clouds only in absorption spectra (Neufeld et al. 2010), similarly indicating a depletion. Very little is known about other hydrogen halides ( $\mathrm{HBr}, \mathrm{HI})$.

Under the hypothesis that comets would contain pristine protostellar material, they would be prime candidates to provide information about halogens in such clouds. Bockelée-Morvan et al. (2014) measured the $\mathrm{HF} / \mathrm{H}_{2} \mathrm{O}$ ratio in the coma of comet $\mathrm{C} / 2009 \mathrm{P} 1$ (Garradd) with marginal significance to be $(1.8 \pm 0.5) \times 10^{-4}$. Attempts to obtain $\mathrm{HCl} / \mathrm{H}_{2} \mathrm{O}$ have resulted in upper limits of $2.2 \times 10^{-4}$ for $\mathrm{C} / 2009 \mathrm{P} 1$ (Garradd) and $1.1 \times 10^{-4}$ for $103 \mathrm{P} /$ Hartley 2 , the former being an Oort cloud comet and the latter a Jupiter-family comet, both suggesting an $\mathrm{HCl} / \mathrm{H}_{2} \mathrm{O}$ depletion. As these upper limits are of the order of the solar values, a clear measurement of the halogen abundances in comets is needed to relate comets to other Solar system bodies in order to trace back their history.

\section{DETECTION OF HALOGEN-BEARING COMPOUNDS}

The European Space Agency's Rosetta mission to 67P/ChuryumovGerasimenko (67P/C-G) offered an unprecedented opportunity to examine a comet up close. The Double Focusing Mass Spectrometer (DFMS) of ROSINA, the Rosetta Orbiter Spectrometer for Ion and Neutral Analysis (Balsiger et al. 2007), is the instrument of choice for examining the comet's volatile inventory in situ (Le Roy et al. 2015). We have studied the halogen-bearing compounds in the coma with DFMS on 67P/C-G's inbound journey during four periods, while the gas production increased towards perihelion and as the latitude of the subsolar point on the comet moved from the Northern to the Southern hemisphere.

\subsection{DFMS operating principle}

The DFMS mass spectrometer was operated both in neutral and ion mode. Here, we use data collected in neutral mode in which only neutral cometary gas is detected, while coma ions cannot reach the detector (Calmonte et al. 2016). A fraction of the neutral gas is ionized and/or fragmented by electron impact ionization in the ion source. Only ion fragments in a narrow range around a certain commanded mass-over-charge ratio $m / Z$ pass through the analyser and impact on a microchannel plate (MCP), creating an electron avalanche that is recorded by a Linear Electron Detector Array chip (LEDA) with two rows of 512 pixels each. The data are obtained as Analog-to-Digital Converter (ADC) counts as a function of LEDA pixel number. The instrument is commanded to scan over a sequence of different $m / Z$ values. A well-established methodology, as described in detail in Le Roy et al. (2015), is used to convert the raw DFMS data into fragment ion intensity as a function of $m / Z$.

\subsection{Time periods of interest}

The most significant fluxes of coma neutrals, including halogenbearing gases, are observed when the spacecraft is close to the comet and/or when the comet is active (close to perihelion). High-mass resolution DFMS data with sufficient signal-to-noise ratio have been obtained during the comet's inbound journey towards perihelion. Special emphasis is given to the time periods indicated in Fig. 1: (A) the $10 \mathrm{~km}$ orbit period when in situ neutral densities were obtained with high-signal-to-noise ratio, (B1 and B2) the close flybys at 8 and $13 \mathrm{~km}$, (C) the period between equinox and perihelion in 2015 May when the Southern hemisphere became the dominant gas source and (D) the period around perihelion when comet activity ensured significant flux despite Rosetta's larger distance from the nucleus. We have eliminated all data during and shortly after significant spacecraft attitude changes, which might lead to spacecraft outgassing (Schläppi et al. 2010), as well as times when the instrument was not pointing at the comet centre to within $5^{\circ}$. These time periods cover all possible latitudes, longitudes, comet-spacecraft distances and comet-sun distances. 


\subsection{Fragments of halogen-bearing compounds}

Because of the fragmentation of molecules in the DFMS ion source, hydrogen halides can be detected in principle in the form of the singly charged fragmentation products $\mathrm{F}, \mathrm{HF},{ }^{35} \mathrm{Cl}$ and ${ }^{37} \mathrm{Cl}, \mathrm{H}^{35} \mathrm{Cl}$ and $\mathrm{H}^{37} \mathrm{Cl},{ }^{79} \mathrm{Br}$ and ${ }^{81} \mathrm{Br}$, and $\mathrm{H}^{79} \mathrm{Br}$ and $\mathrm{H}^{81} \mathrm{Br}$; we did not detect any iodine. The mass spectra shown in Fig. 2 demonstrate that the signal was sufficiently strong to detect halogen-bearing species in 67P's coma for the first time.

Fragment ion species are detected in the form of peaks with a specific shape. To determine the number of fragment ions registered by the detector, a peak fitting algorithm is used which approximates the mass peaks by a sum of two co-centred Gaussians (see e.g. De Keyser et al. 2015), without any a priori knowledge of the identity of the ions. Despite the high-mass resolution, DFMS spectra can be hard to interpret because of the overlapping of mass peaks. If the peaks belong to species with a comparable abundance, disentangling them with the peak fitting process is still possible, depending on the magnitude of the mass difference between the species. However, reliably distinguishing the contribution of a low-abundance species superposed on a high-abundance peak can become difficult, if not impossible.

As shown in Table 1 , at $m / Z=19 \mathrm{u} / \mathrm{e}$ and $20 \mathrm{u} / \mathrm{e}$ the abundant water-related fragment ions ${ }^{18} \mathrm{OH}$ and $\mathrm{H}_{2}^{18} \mathrm{O}$ can overlap $\mathrm{F}$ and $\mathrm{HF}$, respectively. They can even completely obscure them at times when the water flux is high. An example can be seen for $m / Z=20 \mathrm{u} / \mathrm{e}$ in Fig. 2 (top panel). For ${ }^{35} \mathrm{Cl}$ and $\mathrm{H}^{35} \mathrm{Cl}$ at $35 \mathrm{u} / \mathrm{e}$ and $36 \mathrm{u} / \mathrm{e}$, there is an overlap with the sulphur-bearing species $\mathrm{H}^{34} \mathrm{~S}$ and $\mathrm{H}_{2}^{34} \mathrm{~S}$, respectively. At $m / Z=36 \mathrm{u} / \mathrm{e}$, also another overlapping species, ${ }^{36} \mathrm{Ar}$, is present, as reported by Balsiger et al. (2015) and shown in Fig. 2 (middle panel). $\mathrm{H}^{37} \mathrm{Cl}$ cannot be determined accurately because of its small mass difference with doubly charged $\mathrm{CS}_{2}$. Although it is in principle possible to detect singly charged $\mathrm{CS}_{2}$ and to assess the amount of doubly charged ions if one knows the fragmentation pattern, this is not very precise when doubly charged $\mathrm{CS}_{2}$ outnumbers $\mathrm{H}^{37} \mathrm{Cl}$, and also because the time difference of almost $20 \mathrm{~min}$ between the measurement of doubly and singly charged $\mathrm{CS}_{2}$ at 38 and $76 \mathrm{u} / \mathrm{e}$ makes it difficult to reliably infer the $\mathrm{CS}_{2}$ abundance at the moment when $m / Z=38 \mathrm{u} / \mathrm{e}$ is measured. At $m / Z=79,80$, 81 and $82 \mathrm{u} / \mathrm{e}$ bromine-bearing species can be found and there are no overlap issues; an example is given for $m / Z=82 \mathrm{u} / \mathrm{e}$ in Fig. 2 (bottom panel).

The detection system uncertainties on individual measurement points in a given mass spectrum depend on random errors (thermal fluctuations in the LEDA, noise in ADC conversion). The magnitude of these random errors can be estimated from the noise in the spectrum. Possible systematic errors (e.g. uneven aging of the MCP) have been corrected for (Le Roy et al. 2015). Integration below the fitted peak gives the number $v_{\mathrm{Y}}$ of fragment ions $\mathrm{Y}$ that hit the detector during the data collection time $\Delta t$ (typically $20 \mathrm{~s}$ ); the relative uncertainty on $v_{\mathrm{Y}}$ is significantly smaller than the relative uncertainties on the individual pixel measurements as the random errors partially cancel. As a result, the outcome is fairly precise. This detection system related uncertainty, however, is usually (much) smaller than the uncertainty $\sqrt{v_{\mathrm{Y}}}$ due to the Poisson counting statistics. In particular, for the bromine-bearing species the Poisson uncertainty is large because of their low abundances.

\section{HALOGEN ABUNDANCES IN THE COMA}

We now present quantitative estimates of the neutral halogen abundances in the coma of 67P. After introducing the methodology,
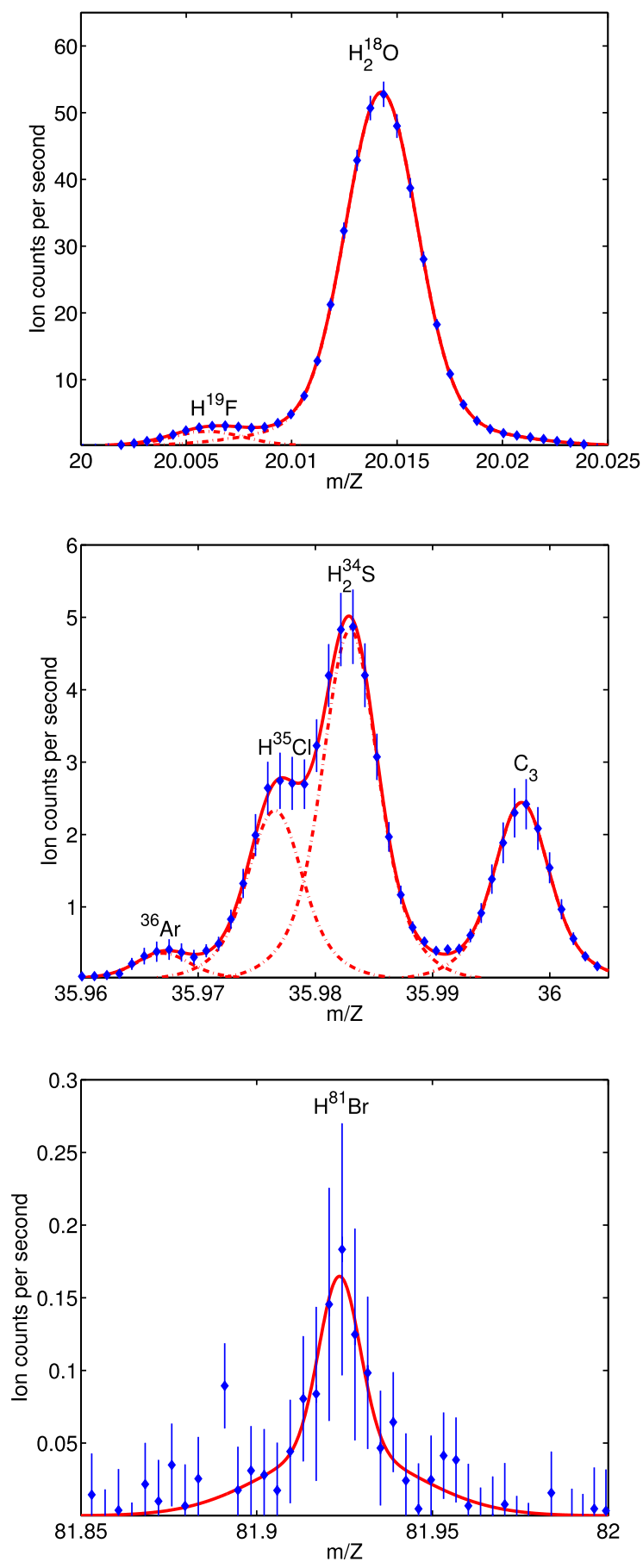

Figure 2. DFMS mass spectra showing $\mathrm{HF}, \mathrm{H}^{35} \mathrm{Cl}$ and $\mathrm{H}^{81} \mathrm{Br}$. The spectra are from 2014 October 23 at mass-over-charge ratio $m / Z=20 \mathrm{u} / \mathrm{e}(08: 35: 32$ UTC), $36 \mathrm{u} / \mathrm{e}$ (12:50:47 UTC) and $82 \mathrm{u} / \mathrm{e}$ (19:40:57 UTC). Error bars indicate the Poisson uncertainty.

we discuss the identity of the parent molecules and the elemental abundances of the halogen-bearing species.

\subsection{Neutral abundances}

The abundance $n_{\mathrm{X}}$ of a specific neutral species $\mathrm{X}$ can be inferred from a detected fragment ion Y using

$n_{\mathrm{X}}=\frac{a C_{\mathrm{Y}}}{U_{\mathrm{X}} V_{\mathrm{Y}} f_{\mathrm{X} \rightarrow \mathrm{Y}}}$ 
Table 1. Halogen and hydrogen halide fragment ions and interfering species. The table lists the commanded mass-over-charge ratio, the halogen-bearing fragment ions (with their mass-over-charge), and the interfering species (with mass-over-charge difference). Note that the $\mathrm{CS}_{2}$ ion near $m / Z=38$ is doubly charged.

\begin{tabular}{|c|c|c|c|c|c|c|}
\hline $\begin{array}{l}\text { Commanded } \\
\text { mass }\end{array}$ & $\begin{array}{c}\text { Interfering } \\
\text { species }\end{array}$ & $\begin{array}{c}\Delta m / Z \\
(\mathrm{u} / \mathrm{e})\end{array}$ & $\begin{array}{l}\text { Main } \\
\text { species }\end{array}$ & $\begin{array}{l}m / Z \\
(\mathrm{u} / \mathrm{e})\end{array}$ & $\begin{array}{l}\text { Interfering } \\
\text { species }\end{array}$ & $\begin{array}{c}\Delta m / Z \\
(\mathrm{u} / \mathrm{e})\end{array}$ \\
\hline 19 & & & ${ }^{19} \mathrm{~F}$ & 18.9984 & ${ }^{18} \mathrm{OH}$ & +0.0086 \\
\hline 20 & & & $\mathrm{H}^{19} \mathrm{~F}$ & 20.0062 & $\mathrm{H}_{2}^{18} \mathrm{O}$ & +0.0086 \\
\hline 35 & & & ${ }^{35} \mathrm{Cl}$ & 34.9689 & $\mathrm{H}^{34} \mathrm{~S}$ & +0.0068 \\
\hline 36 & ${ }^{36} \mathrm{Ar}$ & -0.0092 & $\mathrm{H}^{35} \mathrm{Cl}$ & 35.9767 & $\mathrm{H}_{2}^{34} \mathrm{~S}$ & +0.0068 \\
\hline 37 & & & ${ }^{37} \mathrm{Cl}$ & 36.9659 & & \\
\hline 38 & $\mathrm{CS}_{2}$ & -0.0017 & $\mathrm{H}^{37} \mathrm{Cl}$ & 37.9737 & & \\
\hline 79 & & & ${ }^{79} \mathrm{Br}$ & 78.9183 & & \\
\hline 80 & & & $\mathrm{H}^{79} \mathrm{Br}$ & 79.9262 & & \\
\hline 81 & & & ${ }^{81} \mathrm{Br}$ & 80.9163 & & \\
\hline 82 & & & $\mathrm{H}^{81} \mathrm{Br}$ & 81.9241 & & \\
\hline
\end{tabular}

with $C_{\mathrm{Y}}=c_{\mathrm{Y}}-b_{\mathrm{Y}}$, where $c_{\mathrm{Y}}=v_{\mathrm{Y}} / \Delta t$ denotes the integrated count rate for ion $\mathrm{Y}$ (corrected for instrument gain), $b_{\mathrm{Y}}$ is the integrated spacecraft background count rate for $\mathrm{Y}, U_{\mathrm{X}}$ is the ionization efficiency for neutral $\mathrm{X}, V_{\mathrm{Y}}$ is a factor taking into account iondependent instrument effects for $\mathrm{Y}, f_{\mathrm{X} \rightarrow \mathrm{Y}}$ is the fraction of $\mathrm{Y}$ among all fragmentation products of neutral $\mathrm{X}$ and $a=1.83 \times 10^{-16} \mathrm{~s}$ is an instrument constant taking into account the detection geometry and other instrument characteristics. Very often $S_{\mathrm{X}-\mathrm{Y}}=U_{\mathrm{X}} V_{\mathrm{Y}}$ is called the sensitivity factor. Omitting any possible systematic errors due to inaccurate sensitivities or fragmentation patterns, the relative uncertainty on $n_{\mathrm{X}}$ is the same as the one on $C_{\mathrm{Y}}$.

Even after $10 \mathrm{yr}$ in space, the Rosetta spacecraft is still outgassing (Schläppi et al. 2010) so that the DFMS spectra show contributions from this polluting background gas. This background has been characterized using peak fitting on mass spectra from 2014 August 2, when Rosetta was still far from the comet $(\sim 900 \mathrm{~km})$ and the comet was relatively far away from the $\operatorname{Sun}(\sim 3.5 \mathrm{au})$. For a given fragment ion $Y$, the spacecraft background can significantly contribute to the integrated count rate: $c_{\mathrm{Y}}$ and $b_{\mathrm{Y}}$ may be of comparable magnitude, hence an accurate background correction is needed. A background correction was performed for $\mathrm{HF}$ and $\mathrm{HCl} ; \mathrm{HBr}$ was never detected in the background spectra.

Because $\mathrm{HF}, \mathrm{HCl}$ and $\mathrm{HBr}$ are highly corrosive compounds, the sensitivities and fragmentation patterns for these species have not been determined experimentally with the twin instrument in the calibration facility. The instrument sensitivities for $\mathrm{HF}, \mathrm{F}, \mathrm{HCl}, \mathrm{Cl}, \mathrm{HBr}$ and $\mathrm{Br}$ have been calculated using literature data on electron ionization cross-sections for these compounds from Vinodkumar et al. (2010), together with the known mass/charge dependent transmission and detection efficiencies for the fragmentation products in DFMS. The following sensitivity values were used: $S_{\mathrm{F}-\mathrm{F}}=9.75 \times 10^{-20} \mathrm{~cm}^{3}, S_{\mathrm{HF}-\mathrm{HF}}=S_{\mathrm{HF}-\mathrm{F}}=$ $1.63 \times 10^{-19} \mathrm{~cm}^{3}, S_{\mathrm{Cl}-\mathrm{Cl}}=2.45 \times 10^{-19} \mathrm{~cm}^{3}, S_{\mathrm{HCl}-\mathrm{HCl}}=S_{\mathrm{HCl}-\mathrm{Cl}}=$ $2.58 \times 10^{-19} \mathrm{~cm}^{3}, S_{\mathrm{Br}-\mathrm{Br}}=5.66 \times 10^{-19} \mathrm{~cm}^{3}$ and $S_{\mathrm{HBr}-\mathrm{HBr}}=$ $S_{\mathrm{HBr}-\mathrm{Br}}=5.76 \times 10^{-19} \mathrm{~cm}^{3}$; these numbers are believed to be precise within a factor of 2 (Calmonte et al. 2016). The same values have been used for all corresponding isotopes.

Time profiles of the neutral abundances have been assembled from the analysis of the individual spectra. This is illustrated for period (A) in Fig. 3. The figure shows how the halogen halide and the water abundances from DFMS, as well as the total neutral gas number density from the COmet Pressure Sensor (COPS), which is also part of ROSINA (Balsiger et al. 2007), vary more or less in sync. Most of the time, DFMS with its $20^{\circ} \times 20^{\circ}$ field of view in neutral mode captures gas originating essentially from all over the visible illuminated surface (Bieler et al. 2015, except when the spacecraft is very close to the comet and/or when there is significant off-pointing). The observed density variations reflect the size of this surface as seen from Rosetta while the comet rotates. It is therefore not surprising that $\mathrm{H}_{2} \mathrm{O}$ and the hydrogen halides vary in phase, showing that the halides are of cometary origin. Note, however, that the hydrogen halide to water ratio does not remain constant.

To correlate the abundances of two neutral species, one has to interpolate the respective time profiles in time: DFMS scans the entire mass range by stepping through all possible commanded $m / Z$ values, so that abundances for different neutral species are derived from spectra taken at different times. Such interpolation may introduce unwanted inaccuracies. We therefore interpolate the abundances of the species that is measured most frequently on to the time-scale of the species measured less frequently (only in this manner does one obtain a set of statistically independent ratios). Interpolation is only allowed if the time difference between successive measurements for the neutral to be interpolated is less than $1 \mathrm{~h}(\sim 1 / 12$ th of the comet's rotation period). Uncertainties on the interpolated values are obtained using error propagation.

\subsection{Parent molecule identity}

The identity and quantity of the fragment ions detected by DFMS are linked to the identities and abundances of the neutrals that entered the instrument. An important element for determining the neutral composition is the fragmentation patterns for each neutral species. Table 2 summarizes the fragmentation patterns as given by the National Institute of Standards and Technology (NIST) (Stein et al. 2017). It should be noted that the fragmentation patterns depend on the electron energies (70 eV for NIST, $45 \mathrm{eV}$ in DFMS) and the design of the ion source (filament geometry and electric potentials). Note that the doubly charged ions are ignored, and that the fragmentation patterns are considered to be essentially identical for all isotopes.

As illustrated in Fig. 4, the DFMS data show roughly constant proportions (within the error margins) between the hydrogen halide fragment ions and the corresponding halogen ions: $C_{\mathrm{F}} / C_{\mathrm{HF}}=0.16 \pm 0.01, C_{\mathrm{Cl}} / C_{\mathrm{HCl}}=0.37 \pm 0.02$ and $C_{\mathrm{Br}} / C_{\mathrm{HBr}}=0.75 \pm 0.05$. One has, in general, for halogen halide $\mathrm{HX}$

$\frac{C_{\mathrm{X}}}{C_{\mathrm{HX}}}=\frac{n_{\mathrm{X}} S_{\mathrm{X}-\mathrm{X}} f_{\mathrm{X} \rightarrow \mathrm{X}}+n_{\mathrm{HX}} S_{\mathrm{HX}-\mathrm{X}} f_{\mathrm{HX} \rightarrow \mathrm{X}}}{n_{\mathrm{HX}} S_{\mathrm{HX}-\mathrm{HX}} f_{\mathrm{HX} \rightarrow \mathrm{HX}}}$,

where $C_{\mathrm{X}}$ and $C_{\mathrm{HX}}$ represent the fragment ion abundances corrected for the background, and $n_{\mathrm{X}}$ and $n_{\mathrm{HX}}$ represent the neutral gas 


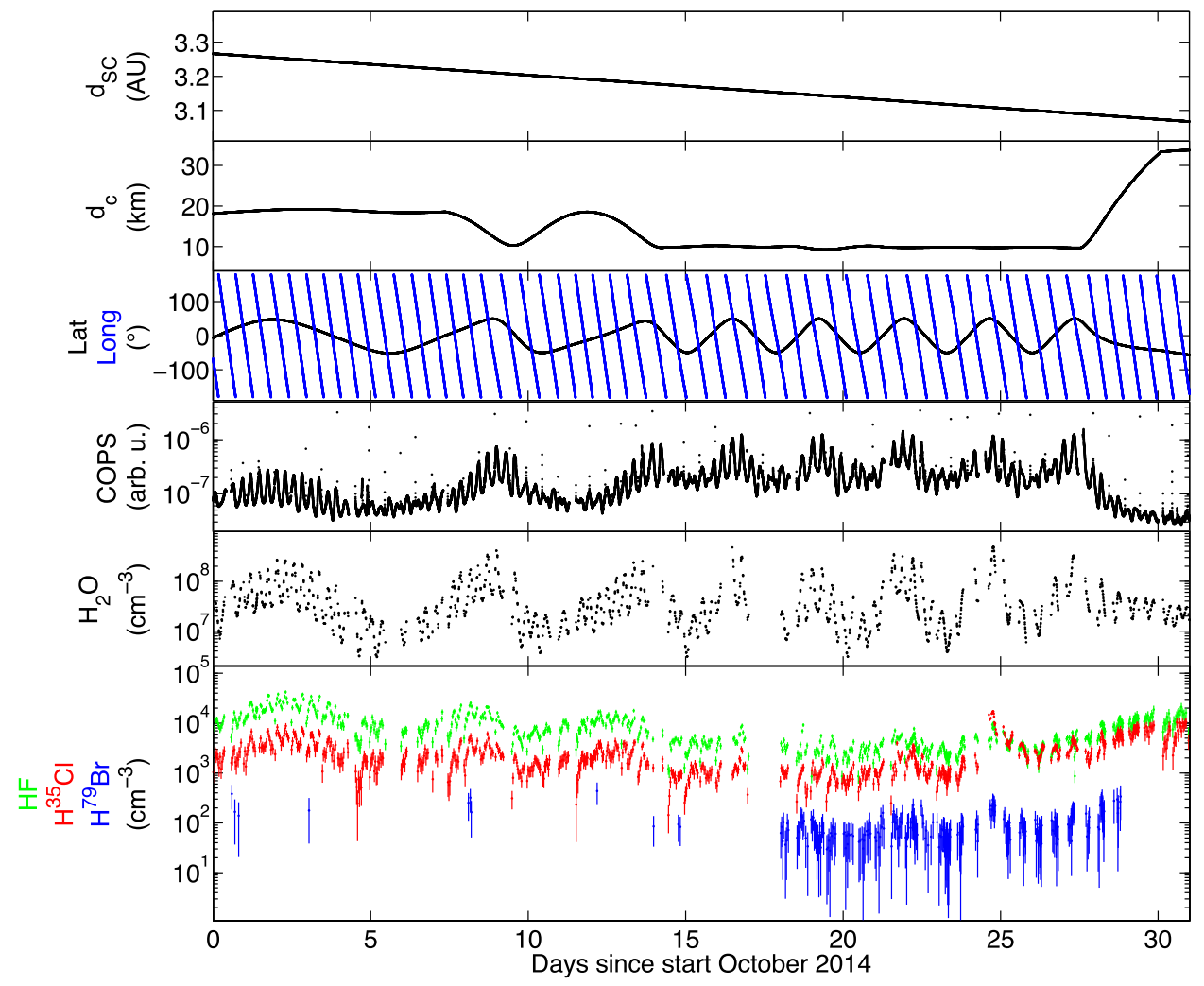

Figure 3. Hydrogen halide time variability in 2014 October. The figure plots the comet's heliocentric distance, Rosetta's cometocentric distance and its latitude and longitude, the neutral coma number density from COPS, and the abundances of $\mathrm{H}_{2} \mathrm{O}$ and of $\mathrm{HF}, \mathrm{H}^{35} \mathrm{Cl}$ and $\mathrm{H}^{79} \mathrm{Br}$ from DFMS. Error bars reflect the Poisson error; systematic errors dominated by the uncertainty on the sensitivities are not indicated here as they would lead to vertical offsets without changing the time variability pattern.

Table 2. Hydrogen halide fragmentation patterns from the NIST data base (Stein et al. 2017), and from DFMS if one assumes that the hydrogen halides are the only parent neutrals.

\begin{tabular}{lllcc}
\hline Parent & & Fragment & NIST fraction & DFMS fraction \\
\hline $\mathrm{F}$ & $\rightarrow$ & $\mathrm{F}^{+}$ & 1.00 & 1.00 \\
$\mathrm{HF}$ & $\rightarrow$ & $\mathrm{HF}^{+}$ & Not given & $0.87 \pm 0.01$ \\
$\mathrm{HF}$ & $\rightarrow$ & $\mathrm{F}^{+}$ & Not given & $0.13 \pm 0.01$ \\
$\mathrm{Cl}$ & $\rightarrow$ & $\mathrm{Cl}^{+}$ & 1.00 & 1.00 \\
$\mathrm{HCl}$ & $\rightarrow$ & $\mathrm{HCl}^{+}$ & 0.85 & $0.73 \pm 0.01$ \\
$\mathrm{HCl}$ & $\rightarrow$ & $\mathrm{Cl}^{+}$ & 0.15 & $0.27 \pm 0.01$ \\
$\mathrm{Br}$ & $\rightarrow$ & $\mathrm{Br}^{+}$ & 1.00 & 1.00 \\
$\mathrm{HBr}$ & $\rightarrow$ & $\mathrm{HBr}^{+}$ & 0.72 & $0.57 \pm 0.02$ \\
$\mathrm{HBr}$ & $\rightarrow$ & $\mathrm{Br}^{+}$ & 0.28 & $0.43 \pm 0.02$ \\
\hline
\end{tabular}

abundances of the halogen and the hydrogen halide. One can simplify this relation by assuming that the DFMS sensitivities $S_{\mathrm{X}-\mathrm{X}}$, $S_{\mathrm{HX}-\mathrm{X}}$ and $S_{\mathrm{HX}-\mathrm{HX}}$ do not differ much, which is plausible given the comparable masses of the corresponding halogen and hydrogen halide. Given the absence of other halogen-bearing species with a significant abundance in the DFMS mass spectra, only two alternatives remain open.

A first option is to assume that the only parent is HX, i.e. that $n_{\mathrm{X}} \ll n_{\mathrm{HX}}$. One then finds

$\frac{C_{\mathrm{X}}}{C_{\mathrm{HX}}}=\frac{f_{\mathrm{HX} \rightarrow \mathrm{X}}}{f_{\mathrm{HX} \rightarrow \mathrm{HX}}}$.
Since the neutral hydrogen halide has only two fragmentation channels, $f_{\mathrm{HX} \rightarrow \mathrm{X}}=1-f_{\mathrm{HX} \rightarrow \mathrm{HX}}$, so that one can rewrite the above expression as

$f_{\mathrm{HX} \rightarrow \mathrm{HX}}=\frac{1}{1+C_{\mathrm{X}} / C_{\mathrm{HX}}}$.

From this we have computed the fragmentation fractions mentioned in the last column of Table 2. These do differ from the NIST ones, which is not surprising. The trend of decreasing proportion of the $\mathrm{HX}$ ion with increasing mass is expected.

A second option is to allow the coma to contain both the halogen and the hydrogen halide. From equation (2) one can then infer

$\frac{n_{\mathrm{X}}}{n_{\mathrm{HX}}}=\frac{\left(C_{\mathrm{X}} / C_{\mathrm{HX}}\right) f_{\mathrm{HX} \rightarrow \mathrm{HX}}-f_{\mathrm{HX} \rightarrow \mathrm{X}}}{f_{\mathrm{X} \rightarrow \mathrm{X}}}$.

Assuming that the NIST fragmentation fractions are applicable to DFMS, we then find that the ratio of neutral $\mathrm{Cl}$ to $\mathrm{HCl}$ in the coma would be $0.16 \pm 0.02$ and the ratio of $\mathrm{Br}$ over $\mathrm{HBr}$ would be $0.26 \pm 0.04$ (where the error margins do not include the uncertainty stemming from the sensitivity estimates). No similar calculation can be done for $\mathrm{F}$ and HF since NIST does not provide the fragmentation pattern. Since the measured proportion of the fragments is fairly constant, the ratio of the neutral halogen and hydrogen halide must be rather constant as well.

All in all, the conclusion is that the hydrogen halides must be the major parent molecules, while we cannot exclude a limited admixture of atomic halogen in the coma gas. 

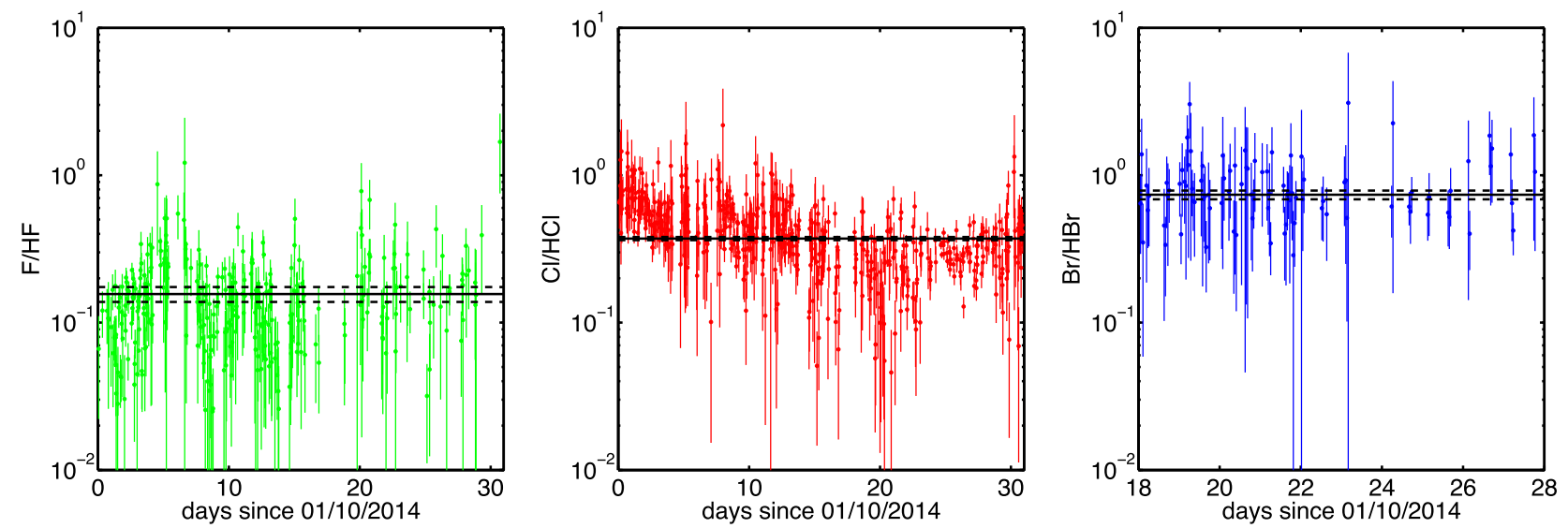

Figure 4. Ratios between halogen fragment ions and hydrogen halide fragment ions observed by DFMS. The solid lines indicate the weighted average, while the dashed lines represent the $1 \sigma$ uncertainty on the average. The ratios appear to be fairly constant within the measurement error margins. The error margins reflect the Poisson uncertainty. Uncertainties on the sensitivities largely cancel out when considering the fragment ratios. Additional uncertainty due to the interpolation of the measurements to a common time-scale has not been included in the error bars, but such errors are limited since measurements of a halogen and the corresponding hydrogen halide usually are performed successively.

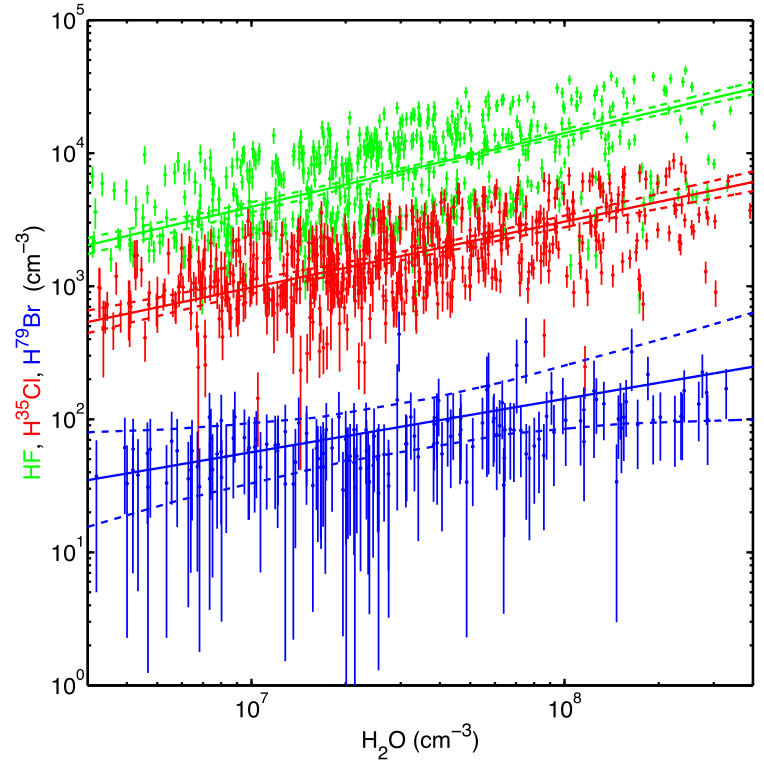

Figure 5. Hydrogen halide abundances relative to water. While the hydrogen halide densities vary with that of water, they are not linearly proportional. The error margins reflect the Poisson uncertainties. Uncertainties on the sensitivities would systematically shift the curves somewhat, without altering their slope. Additional uncertainty due to the interpolation of the measurements to a common time-scale has not been included in the error bars, but such errors are limited as care has been taken to use hydrogen halide and water abundances acquired with minimal time delay. The measurements are from period A (2014 October 1-24).

\subsection{Halogen to oxygen ratios}

The hydrogen halide abundances relative to $\mathrm{H}_{2} \mathrm{O}$ have been used in Bockelée-Morvan et al. (2014) to approximate the halogen-tooxygen element ratios. Fig. 5 compares the hydrogen halide abundances to those of water for period A (2014 October 1-24). Note that the error bars on the water densities are almost invisibly small because of the high counting statistics. As already mentioned before, the $\mathrm{HF}, \mathrm{HCl}$ and $\mathrm{HBr}$ densities vary in sync with those of water, but do not scale linearly with those of water. Exponential curve fitting indicates that $n_{\mathrm{X}} \propto\left(n_{\mathrm{H}_{2} \mathrm{O}}\right)^{\eta}$ with $\eta=0.55 \pm 0.01,0.49 \pm 0.02$ and $0.40 \pm 0.08$, for $\mathrm{HF}, \mathrm{HCl}$ and $\mathrm{HBr}$, respectively, showing that these species are not simply released with water. In a companion paper, De Keyser et al. (2017, this issue) examine the release process in more detail.

The $\mathrm{H}_{2} \mathrm{O}$ abundance is a good proxy for the elemental $\mathrm{O}$ abundance, except at times when $\mathrm{H}_{2} \mathrm{O}$ is not the dominant oxygenbearing volatile (Hässig et al. 2015). We infer the elemental $\mathrm{O}$ abundance in the coma from the abundances of $\mathrm{H}_{2} \mathrm{O}, \mathrm{CO}_{2}, \mathrm{CO}$ and $\mathrm{O}_{2}$, and determine the hydrogen halide abundances in the gas coma relative to oxygen from $\mathrm{F} / \mathrm{O}=\mathrm{HF} / \mathrm{O}, \mathrm{Cl} / \mathrm{O}=\left(\mathrm{H}^{35} \mathrm{Cl}+\mathrm{H}^{37} \mathrm{Cl}\right) / \mathrm{O}$ and $\mathrm{Br} / \mathrm{O}=\left(\mathrm{H}^{79} \mathrm{Br}+\mathrm{H}^{81} \mathrm{Br}\right) / \mathrm{O}$.

The hydrogen halide densities vary with the total gas production of the comet as a result of changes in the illumination conditions and a possible variability over the comet surface, all conditions dictated by comet-Sun distance, latitude and longitude of the subsolar point on the comet, and the relative position of Rosetta relative to the comet and the Sun. To compensate for these effects, we consider elemental abundance ratios of the halogens relative to oxygen, the latter reflecting the neutral gas production. The number densities of the hydrogen halides also vary inversely with the square of the distance, $r^{2}$, as long as no source or loss processes are involved.

De Keyser et al. (2017, this issue) argue that hydrogen halide sublimation may occur not only at the comet surface, but also on dust grains in the inner coma. They explain the observed halogen abundance variations near the nucleus in terms of the sublimation of halogen-enriched water ice mantles on refractory grains. Given the sublimation of the hydrogen halides close to the nucleus, their abundances are best determined at an $\sim 200 \mathrm{~km}$ distance from the nucleus or more; loss processes matter only farther out in the coma, beyond $2000 \mathrm{~km}$. Therefore, $r^{2} n_{\mathrm{F}}, r^{2} n_{\mathrm{Cl}}$, and $r^{2} n_{\mathrm{O}}$, as well as the ratios $\mathrm{F} / \mathrm{O}$ and $\mathrm{Cl} / \mathrm{O}$, should remain constant in the range $\sim 200$ $2000 \mathrm{~km}$. Consequently, the bulk composition has been identified based on periods (C) and (D) when Rosetta was mostly between 200 and $500 \mathrm{~km}$ from the comet. Also, these were the periods upon approach to and around perihelion, when the gas production was highest and when the Southern hemisphere became exposed to sunlight, so that one can expect a larger contribution of unprocessed bulk material from the highly active Southern hemisphere. For these periods, $\mathrm{F} / \mathrm{O}$ varies between $(0.2-4) \times 10^{-4}$ and $\mathrm{Cl} / \mathrm{O}$ between 
Table 3. Comparison of halogen/oxygen ratios (range and average) to various objects.

\begin{tabular}{|c|c|c|c|c|c|c|c|}
\hline & $67 \mathrm{P}$ coma & Other comas & Early Sun & H II regions & Sun & Chondrites & Earth \\
\hline $\mathrm{F} / \mathrm{O}\left(\times 10^{-4}\right)$ & $\begin{array}{l}0.2-4 \\
(0.89)\end{array}$ & $1.8 \pm 0.5^{a}$ & $0.51 \pm 0.12^{b}$ & & $0.7_{-0.3}^{+0.7 c}$ & $1.1 \pm 0.2^{d}$ & $0.16 \pm 0.02^{e}$ \\
\hline $\mathrm{Cl} / \mathrm{O}\left(\times 10^{-4}\right)$ & $\begin{array}{l}2-5 \\
(1.2)\end{array}$ & $\begin{array}{l}<8.0^{f} \\
<2.2^{a} \\
<1.1^{g}\end{array}$ & $3.29 \pm 0.77^{b}$ & $4.3 \pm 0.9^{h}$ & $5.9_{-3.0}^{+6.1 i}$ & $6.8 \pm 1.2^{d}$ & $0.31 \pm 0.16^{e}$ \\
\hline $\mathrm{Br} / \mathrm{O}\left(\times 10^{-6}\right)$ & $\begin{array}{l}1-7 \\
(2.5)\end{array}$ & & $0.68 \pm 0.02^{b}$ & & & $1.4 \pm 0.3^{d}$ & $1.2 \pm 0.4^{e}$ \\
\hline
\end{tabular}

${ }^{a}$ C/2009 P1 (Garradd) from Bockelée-Morvan et al. (2014).

${ }^{b}$ early Sun from Lodders (2010).

${ }^{c}$ Sunspots from Bockelée-Morvan et al. (2014) based on Hall \& Noyes (1969).

${ }^{d} \mathrm{C}_{\text {I }}$ chondrites derived from Lodders (2010).

${ }^{e}$ Earth derived from Allègre, Manhès \& Lewin (2001).

${ }^{f} \mathrm{C} / 1995$ O1 Hale-Bopp from Lis et al. (1997).

${ }^{g}$ 103P/Hartley 2 from Bockelée-Morvan et al. (2014).

${ }^{h} \mathrm{H}$ II regions from Bockelée-Morvan et al. (2014) based on Garcia-Rojas \& Esteban (2007).

${ }^{i}$ Sunspots from Bockelée-Morvan et al. (2014) based on Hall \& Noyes (1972).

$(2-5) \times 10^{-4}$ with a weighted average bulk value of $8.9 \times 10^{-5}$ for $\mathrm{F} / \mathrm{O}$ and $1.2 \times 10^{-4}$ for $\mathrm{Cl} / \mathrm{O}$. Since there are bromine measurements only close to the comet as count rates are too low farther out, we rely on data from period (A). For $\mathrm{Br} / \mathrm{O}$ the range is $(1-7) \times 10^{-6}$ with a weighted average of $2.5 \times 10^{-6}$, which can be considered as a lower bound for the bulk composition. If the hydrogen halides indeed are the major halogen-bearing species, the ratios given above are good proxies for the halogen-to-oxygen ratios. The ratios given above are subject to a systematic error that stems largely from the uncertainties on the sensitivities, believed to be within a factor of 2 (Calmonte et al. 2016).

This composition is compared to that of other objects in Table 3. The F/O value for $67 \mathrm{P} / \mathrm{C}-\mathrm{G}$ is, within the uncertainty margins, quite similar to the Solar system value inferred from the present-day solar composition and a model of solar evolution (Lodders 2010), and to the values found in C/2009 P1 Garradd (volatiles), Ci chondrites (refractory material) and sunspots. The terrestrial F/O ratio is, however, significantly lower. The $\mathrm{Cl} / \mathrm{O}$ ratio is similarly comparable to all other values, except the terrestrial one. Very little is known about $\mathrm{Br} / \mathrm{O}$. These halogen-to-oxygen ratios are compatible with the hypothesis that all halogens were locked up in the form of hydrogen halides on pre-solar grains and were incorporated in the comet when it was formed.

$\mathrm{The} \mathrm{Cl} / \mathrm{F}$ ratio tends to fluctuate around 1.7 (average for periods $\mathrm{C}$ and $\mathrm{D}$, reflecting the bulk composition, varying between 0.5 and 7.0). The uncertainty on this ratio is dominated by the systematic errors on the sensitivities; by considering the ratio, these may partially cancel. This bulk $\mathrm{Cl} / \mathrm{F}$ value is comparable to the upper limit of $1.2 \pm 0.4$ for comet C/2009 P1 (Garradd) from Bockelée-Morvan et al. (2014). A comparison to solar and meteorite ratios is difficult because these address the total abundance ratio and that of refractory material, respectively, rather than the volatile material only. In addition, meteorite ratios show a strong heterogeneity within a sample depending on mineralogical composition, differences among meteorites and possible alteration due to volatile loss after landing on Earth. Solar and chondritic $\mathrm{Cl} / \mathrm{F}$ are typically around 6 or more (Lodders 2010; Ménard et al. 2013). Note that this corresponds to the upper end of the range observed in $67 \mathrm{P} / \mathrm{C}-\mathrm{G}$. For the ratios $\mathrm{Br} / \mathrm{F}$ and $\mathrm{Br} / \mathrm{Cl}$ involving bromine, values of 0.04 (between $0.02-0.10$ ) and $0.08(0.02-0.20)$, respectively, are found (average and ranges for part of period A). A comparison is even harder due to the absence of measurements in comets. In chondrites the $\mathrm{Br} / \mathrm{Cl}$ ratio is around 0.002 (Lodders 2010), for Martian rocks and meteorites it is 0.002 0.05 (Cartwright, Gilmour \& Burgess 2013; Squyres et al. 2012), and for Earth with considerable processing it goes up even higher (Allègre et al. 2001).

\section{ISOTOPIC RATIOS}

Isotopic ratios can be obtained accurately since fragmentation in the ion source and instrument sensitivity is essentially the same for both isotopes (all isotopic measurements presented in this paper were made at the same detector gain settings). Systematic errors associated with the instrument sensitivities are thus removed by considering the ratio of the abundances of both isotopes. If the measurements of two isotopes $\mathrm{X}$ and $\mathrm{Y}$ are interpolated on to the same time-scale, the isotopic ratio can be obtained from

$r_{\mathrm{X} / \mathrm{Y}}=\frac{n_{\mathrm{X}}}{n_{\mathrm{Y}}}=\frac{c_{\mathrm{X}}-b_{\mathrm{X}}}{c_{\mathrm{Y}}-b_{\mathrm{Y}}}$,

where we correct for the presence of $\mathrm{X}$ and $\mathrm{Y}$ in the background. The overall isotopic ratio is obtained from the sum of all time-correlated measurements of isotope $\mathrm{X}$ divided by the sum of all time-correlated measurements of isotope Y. The uncertainty is obtained by error propagation.

The isotopic ratio for ${ }^{37} \mathrm{Cl} /{ }^{35} \mathrm{Cl}$ has been obtained from the atomic chlorine fragments in the 2014 October 1-31 period (Fig. 6, top). The elemental ${ }^{81} \mathrm{Br} /{ }^{79} \mathrm{Br}$ ratio is obtained from a weighted average of the $\mathrm{H}^{81} \mathrm{Br} / \mathrm{H}^{79} \mathrm{Br}$ (Fig. 6, bottom) and ${ }^{81} \mathrm{Br} /{ }^{79} \mathrm{Br}$ (not shown) ion fragment ratios (sufficient signal only for the 2014 October $18-28$ period). An isotopic ratio of $0.29 \pm 0.02$ is obtained for ${ }^{37} \mathrm{Cl} /{ }^{35} \mathrm{Cl}$ and of $0.95 \pm 0.07$ for ${ }^{81} \mathrm{Br} /{ }^{79} \mathrm{Br}$. A comparison with the values for other Solar system objects is presented in Table 4. It turns out that these values are compatible with those for the early Sun, Earth, Moon, Mars, asteroids and meteorites, within the measurement uncertainties.

\section{HALOGENS IN REFRACTORY COMET MATERIAL}

While ROSINA gives insights on the composition of the volatile fraction, Rosetta's dust composition instrument COSIMA (COmetary Secondary Ion Mass Analyzer; Kissel et al. 2007) 

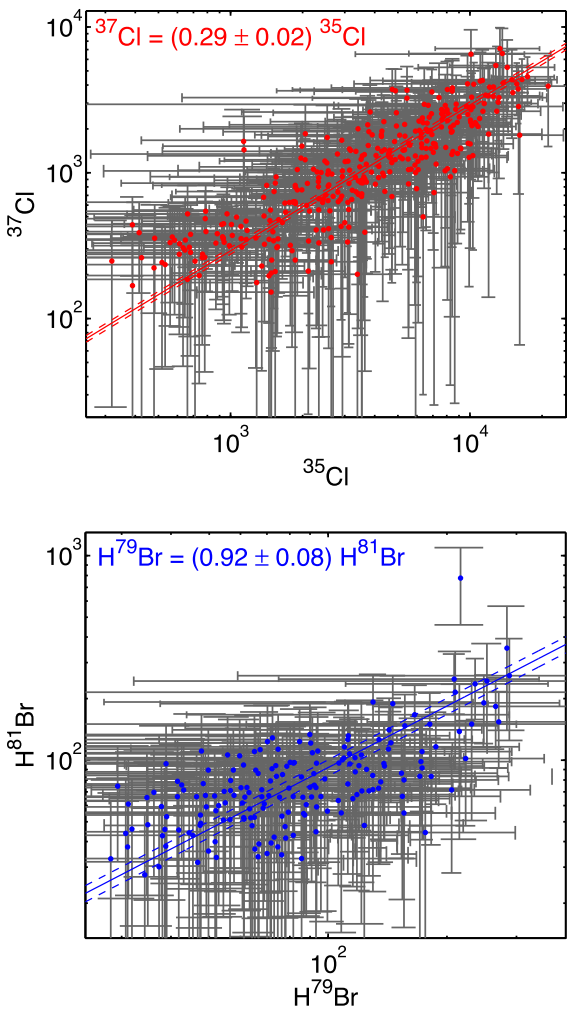

Figure 6. Chlorine and bromine isotopes. Correlating the abundances of the ${ }^{37} \mathrm{Cl}$ and ${ }^{35} \mathrm{Cl}$ fragments (2014 October 1-31) and of the $\mathrm{H}^{79} \mathrm{Br}$ and $\mathrm{H}^{81} \mathrm{Br}$ fragments (2014 October 19-29) provides the corresponding isotopic ratios. The error margins reflect the Poisson uncertainties. Uncertainties on the sensitivities would systematically shift the data by nearly equal amounts on both axes, so that the isotopic ratio would remain unaffected. Additional uncertainty due to the interpolation of the measurements to a common timescale has not been included in the error bars, but such errors are limited as spectra for the corresponding isotopes are acquired with little time delay. provides complementary information on the presence of halogens in refractory dust grains.

\subsection{COSIMA operating principle}

COSIMA is designed to capture and image cometary dust particles and determine the composition of their top surface layers by time-offlight secondary ion mass spectrometry. The instrument is provided with 24 target assemblies of 3 targets covered with gold, silver, palladium or platinum, each $10 \mathrm{~mm} \times 10 \mathrm{~mm}$ in size to capture dust particles. COSIMA can expose each target assembly and collect cometary dust particles at low velocity $\left(\right.$ a few $\mathrm{m} \mathrm{s}^{-1}$ ) to preserve their integrity. Images of the particles are taken and specific particles are selected for analysis. During analysis, the cometary particle (and/or target plate material) is sputtered by means of an indium primary ion beam. COSIMA can be operated to collect either positive or negative secondary ions from the sputtered surface. Depending on the sampled spot, individual mass spectra may contain secondary ions from the cometary particle, the target surface or both.

\subsection{Dust particle 3D0-Kerttu}

We will focus on the dust particle 3D0-Kerttu, which was collected between 2014 October 18 and 24 (period A) on a porous gold substrate. The sample temperature was about $283 \mathrm{~K}$. Halogens have been observed as negative secondary ions. The secondary ions are emitted from the area analysed by the primary indium ion beam. Due to the size of the beam and the size of the cometary particle, most of the time the mass spectra present secondary ions from the particle but also from the primary beam $\left({ }^{115} \mathrm{In}^{+}\right.$at $\left.m / Z=114.90 \mathrm{u} / \mathrm{e}\right)$ and from the surrounding target background, in particular gold ions at $m / Z=196.97$ and ion fragments of a common pollutant molecule detected in TOF-SIMS experiments, PolyDiMethylSiloxane polymers (PDMS). PDMS is extremely efficiently ionized and allows the signal to be normalized using the intensity of the peak at $m / Z=74.98 \mathrm{u} / \mathrm{e}$ corresponding to $\left(\mathrm{CH}_{3}\right) \mathrm{SiO}_{2}^{-}$, a characteristic fragment of PDMS (75PDMS), in order to compare the mass spectra. To

Table 4. Isotopic ratios for various Solar system bodies.

\begin{tabular}{|c|c|c|c|c|c|c|c|}
\hline & $67 \mathrm{P}$ coma & Early Sun & Vesta & Moon & Mars & Chondrites & Earth \\
\hline${ }^{37} \mathrm{Cl} /{ }^{35} \mathrm{Cl}$ & $0.29 \pm 0.02^{a}$ & $\begin{array}{c}0.3198^{b} \\
0.31 \pm 0.01^{c}\end{array}$ & $0.3196-0.3207^{d}$ & $0.3198-0.3222^{e}$ & $\begin{array}{l}0.3195-0.3197^{f} \\
0.3180-0.3196^{g}\end{array}$ & $0.3193-0.3197^{h}$ & $\begin{array}{l}0.3200^{i} \\
0.3197^{j} \\
0.3196^{k}\end{array}$ \\
\hline
\end{tabular}

${ }^{a}$ Average from the ${ }^{35} \mathrm{Cl}$ and ${ }^{37} \mathrm{Cl}$ fragment abundances; the uncertainty is the $1 \sigma$ margin on the average.

${ }^{b}$ early Sun value from Lodders (2010).

${ }^{c}$ protostellar core value in present-day molecular clouds in the local galactic environment from Kama et al. (2015).

${ }^{d}$ range for volatiles believed to be from Vesta, values from Barrett et al. (2016).

${ }^{e}$ range for lunar mare material collected by Apollo, and for lunar meteorites (Shearer et al. 2014; Boyce et al. 2015; Barrett et al. 2016.

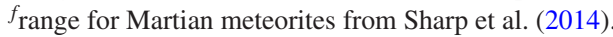

${ }^{g}$ range for rocks in Gale crater analysed by NASA's Curiosity rover (Farley et al. 2016).

${ }^{h}$ range of values for carbonaceous, ordinary and enstatite chondrites from Sharp \& Draper (2013).

${ }^{i}$ average from measurements in a variety of terrestrial reservoirs (de Groot 2009a,b).

${ }^{j}$ NIST Standard Reference Material 975.

${ }^{k}$ Standard Mean Ocean Chlorine (SMOC).

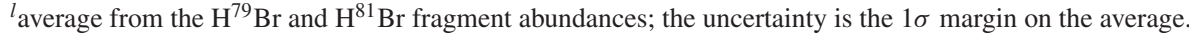

$m_{\text {average from the }}{ }^{79} \mathrm{Br}$ and ${ }^{81} \mathrm{Br}$ fragment abundances; the uncertainty is the $1 \sigma$ margin on the average.

${ }^{n}$ weighted average from both $\mathrm{Br}$ and $\mathrm{HBr}$ measurements.

${ }^{o}$ range for stony meteorites from Wyttenbach, Von Gunten \& Scherle (1965).

${ }^{p}$ NIST Standard Reference Material 977. 


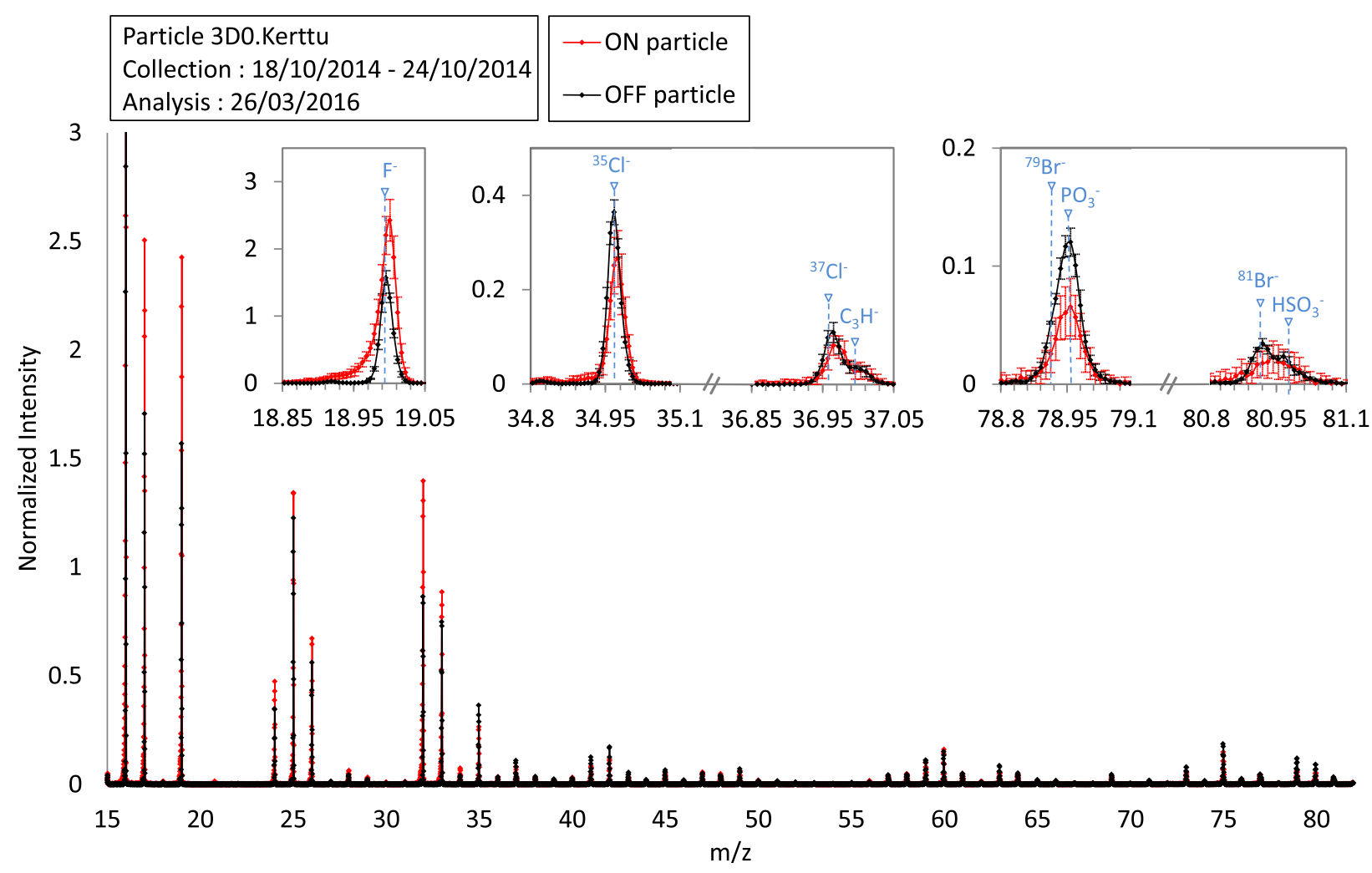

Figure 7. Halogen content on particle 3D0-Kerttu as detected by COSIMA. The particle was collected between 2014 October 18 and 24 and analysed in 2016 March. The detected halogen flux is normalized to the intensity of the $\left(\mathrm{CH}_{3}\right) \mathrm{SiO}_{2}^{-}$fragment of the PDMS material on the target. The halogen/75PDMS ratio detected on the particle (red) and on the gold target next to the particle (black) differs significantly only for F.

Table 5. Dust particle over target substrate (ON/OFF particle) ratios for each peak of halogen species. The ON and OFF abundances are normalized to 75PDMS.

\begin{tabular}{|c|c|c|c|}
\hline & $\frac{I_{\mathrm{X}}}{I_{75 \mathrm{PDMS}}} \mathrm{ON}$ & $\frac{I_{\mathrm{X}}}{I_{75 \mathrm{PDMS}}}$ OFF & ON/OFF \\
\hline $\mathrm{F}^{-}$ & $14.12 \pm 0.71$ & $6.33 \pm 0.45$ & $2.23 \pm 0.27$ \\
\hline${ }^{35} \mathrm{Cl}^{-}$ & $1.42 \pm 0.09$ & $1.59 \pm 0.12$ & $0.89 \pm 0.12$ \\
\hline${ }^{37} \mathrm{Cl}^{-}$ & $0.39 \pm 0.03$ & $0.46 \pm 0.04$ & $0.85 \pm 0.14$ \\
\hline${ }^{79} \mathrm{Br}^{-}$ & $0.23 \pm 0.02$ & $0.40 \pm 0.04$ & $0.57 \pm 0.11$ \\
\hline${ }^{81} \mathrm{Br}^{-}$ & $0.11 \pm 0.01$ & $0.15 \pm 0.01$ & $0.71 \pm 0.12$ \\
\hline
\end{tabular}

find out whether the 3D0-Kerttu dust particle contains halogens, the halogen signals relative to 75PDMS obtained on the cometary dust particle (ON particle) are compared to those measured on the target (OFF particle). Fig. 7 illustrates that this comparison is conclusive only for fluorine. Table 5 gives the dust particle over target substrate (ON/OFF particle) ratios for each peak of halogen species. The $\mathrm{ON} / \mathrm{OFF}$ particle ratio is greater than 1 only for fluorine. The ratios may be a bit biased due to interferences between ${ }^{37} \mathrm{Cl}^{-}$and $\mathrm{C}_{3} \mathrm{H}^{-}$at nominal $m / Z=37 \mathrm{u} / \mathrm{e}$, between ${ }^{79} \mathrm{Br}^{-}$and $\mathrm{PO}_{3}^{-}$at $m / Z=79 \mathrm{u} / \mathrm{e}$ and between ${ }^{81} \mathrm{Br}^{-}$and $\mathrm{HSO}_{3}^{-}$at $m / Z=81 \mathrm{u} / \mathrm{e}$. Analysis of more dust grains, collected in different periods, is needed to assess whether fluorine is also found in other particles, and whether chlorine and bromine are not detected at all.

\section{CONCLUSIONS}

We have reported the first in situ observations of halogens $(\mathrm{F}, \mathrm{Cl}, \mathrm{Br})$ in a cometary atmosphere by Rosetta/ROSINA-DFMS. The main findings are as follows: (i) The halogen content in the volatile fraction on $67 \mathrm{P} / \mathrm{C}-\mathrm{G}$ is mainly in the form of hydrogen halides. This result is compatible with a protosolar origin in view of our understanding of the chemical history of halogens in molecular clouds, where observations and models point to a halogen deficit in the gas phase whereas halogens end up as hydrogen halides on dust grains (Kama et al. 2015).

(ii) The similarity of the halogen-to-oxygen element abundance ratios with the respective solar values points suggests the inclusion of the hydrogen halides into the nucleus during comet aggregation with little further evolution, if any.

(iii) Also the isotopic composition (for the stable isotopes of chlorine and bromine) match the Solar system values, further corroborating the same interpretation.

While the quantitative findings by ROSINA concerning halogens in the volatile comet material should be complemented by further evaluation of the halogens in the refractory component analysed by COSIMA, the overall conclusion is that the halogens are present at the expected abundance levels in the form of hydrogen halides, that already froze out on to grains in the protosolar cloud and that were incorporated into the nucleus as it formed by aggregation beyond the snow line.

\section{ACKNOWLEDGEMENTS}

The authors would like to thank the following institutions and agencies, which supported this work: Work at the Royal Belgian Institute for Space Aeronomy was supported by the Belgian Science Policy Office via PRODEX/ROSINA PEA90020 and 4000107705 and by the F.R.S.-FNRS grant PDR T.1073.14 'Comparative study of atmospheric erosion'. AG acknowledges 
an Additional Researchers Grant (Ministerial Decree of 2014 December 19), as well as an FRIA grant from the F.R.S.FNRS. Work at University of Bern was funded by the State of Bern, the Swiss National Science Foundation and by the European Space Agency PRODEX Programme. Work at MaxPlanck-Institut für Sonnensystemforschung was funded by the Max-Planck Society and BMWI under contract 50QP1302. Work at Southwest Research institute was supported by subcontract \#1496541 from the Jet Propulsion Laboratory. This work was supported by CNES grants at IRAP, LATMOS, LPC2E, Laboratoire Interuniversitaire des Systèmes Atmosphériques, Centre de Recherches Pétrographiques et Géochimiques and by the European Research Council (grant no. 267255 to B. Marty). Work at the University of Michigan was funded by NASA under contract JPL1266313. ROSINA would not give such outstanding results without the work of the many engineers, technicians and scientists involved in the mission, in the Rosetta spacecraft, and in the ROSINA instrument team over the last $20 \mathrm{yr}$ whose contributions are gratefully acknowledged. Rosetta is an ESA mission with contributions from its member states and NASA. We acknowledge herewith the work of the whole ESA Rosetta team. All ROSINA data have been/will be released to the PSA archive of ESA and to the PDS archive of NASA.

\section{REFERENCES}

Allègre C., Manhès G., Lewin É., 2001, Earth Planet. Sci. Lett., 185, 49

Balsiger H. et al., 2007, Space Sci. Rev., 128, 745

Balsiger H. et al., 2015, Sci. Adv., 1, e1500377

Barrett T. J., Barnes J. J., Anand M., Franchi I. A., Greenwood R. C., Charlier B. L. A., Grady M. M., 2016, presentation at "47th Lunar Planet. Sci. Conf.'. Available at: https://www.hou.usra.edu/meetings/ lpsc2016/pdf/2746.pdf

Bieler A. et al., 2015, Nature, 526, 678

Blake G. A., Keene J., Phillips T. G., 1985, ApJ, 295, 501

Bockelée-Morvan D. et al., 2014, A\&A, 562, A5

Boyce J. W., Treiman A. H., Guan Y., Ma C., Eiler J. M., Gross J., Greenwood J. P., Stolper E. M., 2015, Sci. Adv., 1

Calmonte U. et al., 2016, MNRAS, 462, S253

Cartwright J. A., Gilmour J. D., Burgess R., 2013, Geochim. Cosmochim. Acta, 105, 255

Dalgarno A., de Jong T., Oppenheimer M., Black J. H., 1974, ApJ, 192, L37

de Groot P. A., 2009a, in Handbook of Stable Isotope Analytical Techniques Vol. 2. Elsevier, Amsterdam, p. 721 de Groot P. A., 2009b, in Handbook of Stable Isotope Analytical Techniques Vol. 2. Elsevier, Amsterdam, p. 741

De Keyser J. et al., 2015, Int. J. Mass Spectrom., 393, 41

De Keyser J. et al., 2017, MNRAS, this issue

Emprechtinger M., Monje R. R., van der Tak F. F. S., van der Wiel M. H. D., Lis D. C., Neufeld D., Phillips T. G., Ceccarelli C., 2012, ApJ, 756,136

Farley K. A. et al., 2016, Earth Planet. Sci. Lett., 438, 14

Garcia-Rojas J., Esteban C., 2007, ApJ, 670, 457

Hall D. N. B., Noyes R. W., 1969, Astrophys. Lett., 4, 143

Hall D. N. B., Noyes R. W., Ayres T. R., 1972, ApJ, 175, L95

Hässig M. et al., 2015, Science, 347, aaa0276

Jura M., 1974, ApJ, 190, L33

Kama M. et al., 2015, A\&A, 574, A107

Kissel J. et al., 2007, Space Sci. Rev., 128, 823

Le Roy L. et al., 2015, A\&A, 583, A1

Lis D. C. et al., 1997, Earth Moon Planets, 78, 13

Lodders K., 2010, in Goswami A., Reddy B. E., eds, Principles and Perspectives in Cosmochemistry, Chapter. 8. Springer-Verlag, Berlin, p. 379

Ménard J. M., Caron B., Jambon A., Michel A., Villemant B., 2013, presentation at '44th Lunar Planet. Sci. Conf.' Available at: http://www.lpi.usra.edu/meetings/lpsc2013/pdf/2375.pdf

Neufeld D. A., Wolfire M. G., 2009, ApJ, 706, 1594

Neufeld D. A. et al., 2010, A\&A, 518, L108

Peng R., Yoshida H., Chamberlin R. A., Phillips T. G., Lis D. C., Gerin M., 2010, ApJ, 723, 218

Schläppi B. et al., 2010, J. Geophys. Res., 115, A12313

Sharp Z. D., Draper D. S., 2013, Earth Planet. Sci. Lett., 369, 71

Sharp Z., Shearer C., Burger P., Agee C., McKeegan K., 2014, presentation at '45th Lunar Planet. Sci. Conf.' Available at: https://www.hou. usra.edu/meetings/lpsc2014/pdf/1617.pdf

Shearer C. K., Sharp Z. D., Burger P. V., McCubbin F. M., Provencio P. P., Brearley A. J., Steele A., 2014, Geochim. Cosmochim. Acta, 139, 411

Squyres S. W. et al., 2012, Science, 336, 570

Stein S. E., 2017, in Linstrom P. J., Mallard W. G., eds, 'Mass Spectra' by NIST Mass Spec Data Center, NIST Chemistry WebBook, NIST Standard Reference Database Number 69, Mallard. National Institute of Standards and Technology, Gaithersburg, MD

Vinodkumar M., Dave R., Bhutadia H., Antony B. K., 2010, Int. J. Mass Spectrom., 292, 7

Wyttenbach A., Von Gunten H. E., Scherle W., 1965, Geochim. Cosmochim. Acta, 29, 467

This paper has been typeset from a $\mathrm{T}_{\mathrm{E}} \mathrm{X} / \mathrm{L} \mathrm{T} \mathrm{E} \mathrm{X}$ file prepared by the author. 